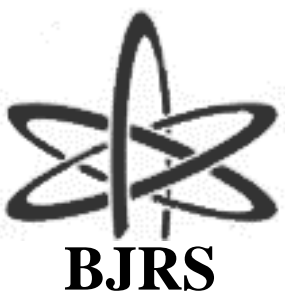
BRAZILIAN JOURNAL $\mathrm{OF}$ RADIATION SCIENCES
02-3A (2014) 01-09

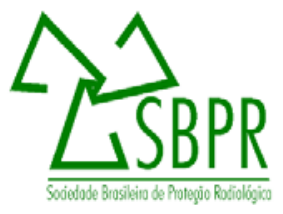

\title{
Safety assessment driving radioactive waste management solutions (sadrwms methodology) implemented in a software tool (safran)
}

\author{
Kinker M. ${ }^{1}$, Avila R. ${ }^{2}$, Hofman D. ${ }^{2}$, Jova Sed L. ${ }^{3}$, Ledroit F. ${ }^{4}$ \\ ${ }^{1}$ International Atomic Energy Agency \\ PO Box 100, 1400 Vienna, Austria \\ M.Kinker@iaea.org \\ 2 FACILIA AB \\ Multrågatan 13, 16254 Vällingby Stockholm, Sweden \\ rodolfo@facilia.se \\ ${ }^{3}$ Centro Nacional de Seguridad Nuclear (CNSN) \\ Calle 28 e/ 5ta y 7ma, Miramar, La Habana, Cuba \\ jovaluis@gmail.com \\ ${ }^{5}$ IRSN \\ PSN-EXP/SSRD/BTE, BP 17 \\ 92262 Fontenay-aux-Roses Cedex \\ frederic.ledroit@irsn.fr
}

\begin{abstract}
In 2004, the International Atomic Energy Agency (IAEA) organized the International Project on Safety Assessment Driving Radioactive Waste Management Solutions (SADRWMS) to examine international approaches to safety assessment for predisposal management of radioactive waste. The initial outcome of the SADRWMS Project was achieved through the development of flowcharts which could be used to improve the mechanisms for applying safety assessment methodologies to predisposal management of radioactive waste. These flowcharts have since been incorporated into DS284 (General Safety Guide on the Safety Case and Safety Assessment for Predisposal Management of Radioactive Waste), and were also considered during the early development stages of the Safety Assessment Framework (SAFRAN) Tool.
\end{abstract}

In 2009 the IAEA presented DS284 to the IAEA Waste Safety Standards Committee, during which it was proposed that the graded approach to safety case and safety assessment be illustrated through the development of Safety Reports for representative predisposal radioactive waste management facilities and activities. To oversee the development of these reports, it was agreed to establish the International Project on Complementary Safety Reports: Development and Application to Waste Management Facilities (CRAFT). The goal of the CRAFT project is to develop complementary 
reports by 2014, which the IAEA could then publish as IAEA Safety Reports. The present work describes how the DS284 methodology and SAFRAN Tool can be applied in the development and review of the safety case and safety assessment to a range of predisposal waste management facilities or activities within the Region.

\section{INTRODUCTION}

Safety assessment is a process which is required to evaluate the safety of radioactive waste management facilities and activities [1-5]. Such assessments, which are iterative in nature, evaluate the potential impact that these facilities or activities could have on human health and the environment.

The SADRWMS (Safety Assessment Driving Radioactive Waste Management Solutions) Project was an international programme of work to examine international approaches to safety assessment in aspects of predisposal radioactive waste management, including waste conditioning and storage. The project commenced in 2004, at an opening meeting at which the original project activities were discussed and agreed. The initial outcome of the SADRWMS Project was achieved through the development of a series of flowcharts which were intended to improve the mechanisms for application of safety assessment methodologies for predisposal management of radioactive materials. Safety assessments for various types of facilities had been carried out for many years, but, prior to SADRWMS, there had not been any international efforts to compare the techniques and methods applied in such assessments for predisposal waste management facilities or activities. Nor had consideration been given to how the results of these assessments should be interpreted and used in decision making on design development or modification, safety upgrades, periodic safety assessment or licensing activities. The SADRWMS project encompassed all types of radioactive waste including disused sources, small volumes, legacy and decommissioning waste, operational waste, and large volume NORM residues.

The original scope, objectives, content and work programme of the SADRWMS International Project envisaged that the main outcomes would be: 
- improved mechanisms for application of safety assessment methodologies for predisposal management of radioactive materials:

- illustration and practical advice on application of safety assessment methodologies using the master flowchart and case studies taken forward through three application working groups.

- development of an integrated and graded approach to addressing a large variety of radioactive materials management challenges.

- to enhance confidence and public acceptability of the pre-disposal management practices by scientific safety assessment approach

- coordinated approaches to regulatory and peer review and justification of safety assessment and development of associated procedures, reflecting state-of-the-art international practice for predisposal management of various types of radioactive waste.

The SADRWMS project was successful in achieving these outcomes. The results of the SADRWMS project have been incorporated into the Safety Guide GSG - 3: "Safety Case and Safety Assessment for Predisposal Management of Radioactive Waste” [6]. In comparing international approaches to safety assessment in those areas, it developed a Safety Assessment Framework (SAFRAN) Tool that implements international best practice in these areas.

\section{DEVELOPMENT OF THE SAFRAN TOOL}

The first outcome stated at the start of the SADRWMS International Project was to improve the mechanisms for application of safety assessment methodologies for predisposal management of radioactive materials. This outcome has been achieved: firstly through the development of a series of flowcharts, and secondly by sponsoring the development of the SAFRAN tool. Between 2005 and 2010 the IAEA developed the SAFRAN tool to help users undertake safety assessment of waste management facilities in a consistent and transparent manner. SADRWMS members provided the technical input necessary to have confidence in the suitability of the SAFRAN tool.

The SAFRAN tool applies the safety assessment methodologies developed by SADRWMS Project. Its main objective is to assist operators, regulators and technical support specialists in 
performing systematic and structured safety assessments in compliance with national regulations, relevant international safety standards, and good international practice. The SAFRAN tool allows the user to visibly, systematically and logically address pre-disposal radioactive waste management challenges in a structured way. It also records the decisions taken in such a way that it constitutes a justifiable safety assessment of the proposed management solutions.

Each SAFRAN project file consists of the following modules: facilities, waste streams, activities, and regulatory framework, methodology and safety assessments. These modules may be accessed in any given order, but some items need pre-defining, e.g. you need to first define a facility before you can start to develop a safety assessment for this facility. Figure 1 illustrates the overall architecture of the current SAFRAN tool.

Facilities. Facilities define the test site, including radioactive waste processing and storage facilities. Physical elements (e.g. roof of a facility, structures, equipment), and safety functions (e.g., shielding, containment) can also be specified in order to assess their adequacy in any given safety assessment.

Activities. This section describes all activities that elements containing radioactive waste will be subjected to. It is linked to the waste stream module, where the connections between elements containing radioactive materials and waste components with the decommissioning or waste management activities are defined. 


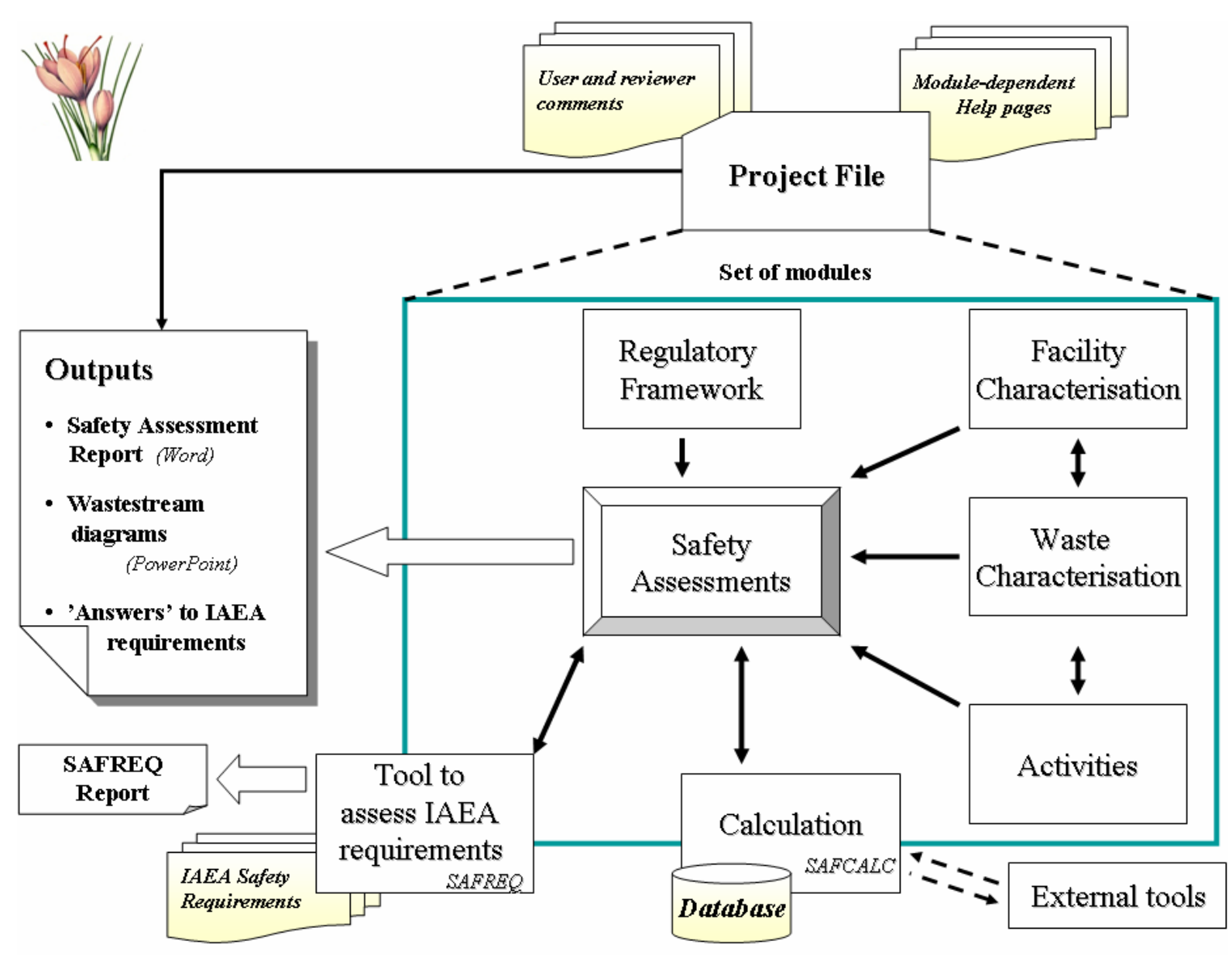

Figure 1. SAFRAN architecture presenting the modules that support the safety assessment.

Waste Streams. Each waste stream consists either of a primary waste component can be defined. Defining the activities performed with this waste component and the respective output of this activity (one or more) is an essential part of this characterization process. The definition of output components involves the determination of the properties subject to be changed and also can handle the conversion of elements containing radioactive materials into radioactive waste through a decommissioning activity. Input data on waste components are needed before an assessment can be carried out. An overview of the waste components defined and their relationship with regard to the different process steps can be illustrated by radioactive waste stream diagrams. The tool also assists assessments for clearance. 
Regulatory Framework. The user must enter user-defined definitions of general regulatory requirements and specify the types of endpoints and criteria to be used in the different safety assessments. Note that, as general requirements, both the optimization principle (ALARA) and the Graded Approach are already included as default. In addition to these qualitative criteria, types of endpoints for quantitative criteria are specified. These can consist in dose or risk criteria, but also can relate to other types of endpoints such as activity releases or activity concentrations in specific media. Clearance levels and criteria are also included in this module.

SAFREQ. This tool enables the user to assess whether IAEA safety standards are being met, with the help of a questionnaire to fill-in and guidance to help answers to be given. Nowadays the SAFREQ Tool is under review and development.

Safety Assessment. A safety assessment consists of the definition of the purpose of the assessment and the assessment approach, the definition of assessment cases for normal operation and for accidental scenarios, the assessment of doses and risks arising from these, and their analysis in terms of regulatory criteria as well as with regard to the design of facilities and processes and required safety elements and safety functions. A safety assessment module is available for all main steps of predisposal radioactive waste management activities. Each of the other modules (i.e. facilities, waste streams, activities, regulatory framework and methodology) is specifically designed to support safety assessments for these activities following the SADRWMS methodologies. The outcome of the safety assessment can be utilized for different purposes, ranging from selecting an adequate site, providing detailed definition of procedures for the operation of a facility, assessing compliance with regulatory criteria, defining monitoring and maintenance requirements, and providing input for development of emergency preparedness plans.

Calculation Tool - SAFCALC. This tool implements standard methodologies and performs dose and risk assessments for a number of scenarios (normal operation and accident conditions) of relevance for safety assessment in waste management. It can be used as a standalone application, or linked to the other SAFRAN modules. SAFCALC directly uses the information supplied when 
defining facilities and waste streams. It should be mentioned that the user is not obliged to use this tool and can introduce the results obtained using other tools.

Other Features. SAFRAN also supports a number of other features which can greatly assist in the documentation of the safety case. These include:

a. help pages to guide the users in filling the various forms within SAFRAN;

b. comments boxes that allow both users and reviewers to record comments, and thus provide a means of dialoguing;

c. link to documents and other electronic material (e.g. pictures, maps) for uploading as part of the safety assessment; and

d. reporting, i.e. create a Microsoft Office $(\mathcal{C}$ Word file that contains all the steps of the safety assessment performed as well as the characteristics of the relevant waste components, facility and waste stream diagrams

\section{COMPLIMENTARY SAFETY REPORTS, DEVELOPMENT AND AP- PLICATION TO WASTE MANAGEMENT FACILITIES (CRAFT)}

In 2009 the draft Safety Guide DS284 “Safety Assessment for Radioactive waste predisposal facilities and activities” [6] was presented to the IAEA Waste Safety Standards Committee, (WASSC). GSG-3 has been written to cover all types of waste management predisposal facilities. As a result it was agreed that the safety guide should be supplemented by a number of complimentary safety reports to help different users. To oversee the development of one of these complimentary safety reports and provide technical support to the ongoing development of SAFRAN it was agreed to establish the Complimentary Safety Reports, Development and Application to Waste Management Facilities (CRAFT) project.

The DS284 methodology can be applied to a range of different types of predisposal waste management facilities or activities. These facilities or activities will vary in nature, size and complexity and will have different hazards associated with them, both from normal operation and from potential accidents. In addition, a predisposal waste management facility or activity could be 
one of several facilities or activities on a site and may be independent of the other facilities, connected to other facilities or an integral part of a larger facility. Commensurately the extent and complexity of the safety case and supporting assessment will differ according to the facility or activity and will also evolve through their lifecycle (e.g. construction, commissioning and operation). In view of these considerations, a graded approach should be applied to the development and review of the safety case and supporting assessment. The guidance and recommendations contained in DS284 is comprehensive and sufficient for the most complex and hazardous facilities. It is the objective of the CRAFT project to illustrate their use in a graded manner to a number of supporting safety reports which cover a range of facilities.

The objective of the CRAFT project is to develop, by 2014, a report, containing illustrative guidance for applying the methodology in DS284 to a range of predisposal waste management facilities or activities with links to the use of the SAFRAN tool, for the IAEA to publish. On completion of the work, the CRAFT project members should consider whether further work should be done on other predisposal waste management options. It is not the intention of the CRAFT project to produce detailed guidance for each type of predisposal waste management facility or activity. Instead the guidance will identify possible ways of addressing the methodology presented in DS284 and will highlight where differences might occur between facilities or activities.

The guidance produced by the CRAFT project will identify ways that the SAFRAN software tool can be used to support the production of the safety assessment called for in DS284.

\section{CONCLUSIONS}

The IAEA carried out the SADRWMS Project to examine international approaches to safety assessment for predisposal management of radioactive waste. An outcome of the SADRWMS Project was the development of flowcharts to improve the mechanisms for applying safety assessment methodologies to predisposal management of radioactive waste. These flowcharts have been incorporated into DS284and have also been considered during the development stages of the SAFRAN Tool. 
The SAFRAN Tool is a freeware software application that can be downloaded from the website (http://www.safran.facilia.se/safran/show/HomePage), which also provides user support, possibility to download test-case examples of SAFRAN use, links to other relevant projects, and a utility for feedback to enable future and ongoing improvement of the software tool. The SAFRAN Tool implements international best practice in these areas. The ongoing CRAFT International Project is developing a report containing guidance for applying the methodology in DS284 to a range of predisposal waste management facilities and activities including the use of the SAFRAN tool.

\section{REFERENCES}

1. IAEA. "Radiation Protection and Safety of Radiation Sources: International Basic Safety Standards”. INTERIM EDITION. IAEA Safety Standards Series, GSR Part 3, IAEA, Vienna, (2013).

2. IAEA. "Principios Fundamentals de Seguridad". Nociones Fundamentales de Seguridad No SF - 1, IAEA, Viena, (2007).

3. IAEA, "Convención Conjunta sobre Seguridad en la Gestión del Combustible Gastado y sobre Seguridad en la Gestión de los Desechos Radiactivos”, INFCIRC/546, Viena, (1998)

4. IAEA, "Gestión previa a las disposición final de desechos radiactivos", Colección de normas de seguridad del OIEA, GSR Parte 5, Viena (2010);

5. IAEA. "Evaluación de la seguridad de las instalaciones y actividades" Requisitos Generales de Seguridad Parte 4 (GSR Parte 4), IAEA, Viena, (2010).

6. IAEA. "Safety Case and Safety Assessment for Predisposal Management of Radioactive Waste”, Safety Guide DS284, IAEA, Vienna (in publication) 